DOI: 10.21892/978-958-5547-64-3.2

\title{
2. El estado constitucional de derecho en Colombia y su incidencia en el sistema jurídico'
}

\author{
Víctor Manuel Cáceres Tovar ${ }^{2}$ \\ María Fernanda Valbuena Batanero ${ }^{3}$
}

\section{Introducción}

La promulgación de la Constitución Política de 1991 hizo nacer en Colombia, y en nuestro sistema jurídico y político, un nuevo modelo de organización que con el tiempo ha sido llamado Estado Constitucional. Al respecto, la nueva Carta declara que Colombia es un Estado de derecho, refiriéndose a que la actividad del Estado está regida por las normas jurídicas, es decir, que se ciñe al derecho, siendo la Constitución la norma jurídica fundamental (C.P. art. 4), y que toda la actividad legal del Estado debe realizarse en el marco de esta. En esta situación concreta, se habla entonces del Estado Constitucional de derecho, el cual contiene una amplia incidencia en nuestro sistema jurídico.

No obstante, su amplio desarrollo doctrinal y jurisprudencial, permanece aún abierta la cuestión sobre qué relaciones existen entre Estado, derecho y Constitución política. Confluencia que está sometida a debates

1 Capítulo de Libro que presenta resultados parciales de la investigación ya terminada, cuyo título es: "Fundamentación Teórica de una Política Criminal Constitucional en Colombia" desarrollada en el marco del Doctorado en Derecho y al interior del Grupo de Investigación: "Red de Política Criminal Sistémica Extrema Ratio UN" (Reconocido y Clasificado en Al por Minciencias 2018) de la Facultad de Derecho, Ciencias Políticas y Sociales de la Universidad Nacional de Colombia.

2 Abogado de la Universidad Autónoma de Colombia. Especialista en Derecho Internacional Humanitario y Derechos Humanos de la Universidad Externado de Colombia. Magister en Derechos Humanos, Estado de derecho y Democracia de la Universidad de Alcalá de Henares, España. Magister en Derecho Penal de la Universidad Libre de Colombia. Doctor en Derecho de la Universidad Nacional de Colombia.

3 Licenciada en Educación Comunitaria de la Universidad Pedagógica Nacional. Magister en Desarrollo Educativo y Social de la Fundación Centro Internacional de Educación y Desarrollo Humano - CINDE. 
sobre sus rasgos definitorios e implicaciones jurídicas, razón por la cual, el objetivo central de este documento académico gravitará teóricamente en establecer una visión preponderantemente constitucional y de derechos humanos, además de qué es lo que debe entenderse por el concepto de Estado Constitucional de derecho, su evolución y la importancia que ha tenido dentro del sistema jurídico colombiano, para lo cual se propone estructuralmente el desarrollo de los siguientes apartados: I. El Estado Constitucional de derecho; II. El Proceso de Constitucionalización en Colombia; III. Incidencia en el Sistema Jurídico Nacional, orden que permite entender el cambio de paradigma que ha tenido el derecho colombiano, al pasar de un Estado de derecho a un Estado Constitucional de derecho que debe gobernar todo el sistema jurídico nacional.

\section{El Estado Constitucional de derecho}

\subsection{La Constitucionalización del derecho}

Según Arrieta (2009), la constitucionalización del derecho se refiere al fenómeno jurídico según el cual el ordenamiento legal de un país, y por tanto el derecho en sí mismo considerado, que en su interpretación y aplicación debe estar regido por la Constitución de dicho país. Ello quiere decir que la norma primaria a la cual debe acompasarse en forma obligatoria el derecho del país respectivo debe ser la Constitución. Para el siglo XIX el orden jurídico giraba en torno del acatamiento ciego de la ley, pero a partir del siglo XX, las cosas cambiaron porque el eje central lo constituye la Carta Magna o carta fundamental. La Constitución pasó de un documento político a volverse un documento eminentemente jurídico (Arrieta, 2009).

Las referencias obligadas sobre el tema de la constitucionalización del derecho, o neoconstitucionalismo, como suelen llamarlo algunos tratadistas, nos lleva obligatoriamente a Europa. En primer lugar, lo constituye la ley fundamental de Boonn (Constitución de Alemania de 1949), y en especial, el surgimiento del Tribunal Constitucional Federal en 1951. En segundo lugar, la Constitución Política italiana de 1947 y la creación de la Corte Constitucional en 1956. En tercer lugar, la creación de la Corte Constitucional en Portugal (1982). En cuarto lugar, el Tribunal Constitucional español del año 1978. En quinto lugar, la Constitución 
Política de Bélgica en el año 1984. Todos ellos dieron un paso fundamental al dotar a sus constituciones de fuerza vinculante, de obligatoria observancia, con plena eficacia y de cumplimiento forzoso (Arrieta, 2009).

Para que se alcanzara este cambio de mentalidad, según Arrieta (2009), se necesitaron históricamente tres grandes transformaciones, que a la postre modificaron el conocimiento convencional en relación con la aplicación de la constitución política: $1^{\circ}$. El reconocimiento de fuerza normativa de la Constitución; $2^{\circ}$. La creación de una jurisdicción constitucional; y $3^{\circ}$. El desarrollo global de una nueva dogmática de la interpretación constitucional. Es así como, a partir de principios del siglo XX se empezó a considerar que la Constitución es norma jurídica, dejando en el pasado la concepción de que la Constitución es un documento político, y, por consiguiente, proyectando hacía el futuro la consideración de que es un texto jurídico con fuerza vinculante y obligatorio que marca el norte que deben seguir las demás leyes, decretos, acuerdos, reglamentos, etc. Así las cosas, la constitucionalización del derecho necesita, como su nombre lo indica, de la Constitución como norma de normas, como Carta Suprema material y formal de donde devienen la legitimidad de las acciones políticas y jurídicas, y los principios e ideologías característicos de los gobiernos, siendo pues el lugar de reunión de los acuerdos mínimos, cuyo establecimiento es un rasgo característico del nuevo modelo de Estado Constitucional.

En cuanto al carácter normativo de la Constitución existen, tomando las ideas de García de Enterría (1985), tres razones para calificar a la Constitución de orden normativo. En primer lugar, es la Constitución la que define el sistema de fuentes formales del derecho dentro del ordenamiento, estableciendo cuáles son los órganos y los procedimientos idóneos para crear normas con fuerza vinculante. En segundo término, la Constitución, en cuanto dotada de valor normativo, se impone tanto a los poderes públicos como a los particulares. Y por último, su jerarquía normativa está garantizada por los mecanismos de control de constitucionalidad existentes. En todos esos contenidos se presenta como un sistema preceptivo que emana del pueblo como titular de la soberanía, en su función constituyente están los preceptos que van dirigidos tanto a los diversos órganos del poder como a los ciudadanos. No obstante, señala Sartori (2005) que las Constituciones deben construir mecanismos que funcionen y que produzcan algo, por 
lo que en consecuencia la preocupación fundamental del profesor Sartori se centra en que las Constituciones se desempeñen como se supone que deben funcionar, con la finalidad de alcanzar buenos gobiernos, por lo que para alcanzar este objetivo es muy probable que las Constituciones deban ser reformadas. Entonces, el problema estriba en saber qué es lo que se necesita cambiar y cómo cambiarlo, considerándose siempre en ideas del mismo autor, que para un buen gobierno o para que el gobierno funcione se debe observar en muy diversos países (derecho comparado), lo que ha marchado bien y lo que no, puntualizando las causas de ello y sugiriendo modificaciones constitucionales para que el mecanismo no encuentre obstáculos en su funcionamiento.

\subsection{El Estado Constitucional}

Según Alexy $\left(1993^{a}\right)$ el objetivo radical del proceso de constitucionalización del derecho no fue sino el impulso básico del constitucionalismo contemporáneo, esto es, la consolidación de modelos de Estado donde existe una Constitución democrática que está por encima de las demás normas, y que establece auténticos límites jurídicos al poder para la garantía de los derechos fundamentales. Bajo esta nueva perspectiva, surge a la postre el concepto ya levemente mencionado de Estado Constitucional o Estado Constitucional de derecho, el cual bajo un estudio propio efectuado por Lancheros - Gámez (2009), goza de algunas particularidades, y comporta algunos efectos que permiten identificarlo y, si se quiere, entenderlo, por lo que vale la pena presentar los resultados logrados por el mismo autor para concebir cómo uno de los principales efectos de aceptar la idea de un Estado constitucional tiene que ver con la constitucionalización del ordenamiento jurídico, lo cual no es más que un proceso de permeabilización de la actividad de todos los actores sociales, políticos, jurídicos y culturales a los principios y las reglas de la Constitución. Tal como lo sugiere Guastini, de quien se tomaron originalmente la enumeración de sus rasgos más relevantes, no todos ellos se presentan con el mismo grado de claridad o intensidad, salvo los dos primeros, sin los cuales no podría hablarse siquiera de constitucionalización (Lancheros Gámez, 2009).

En análisis de Lancheros-Gámez (2009), lo primero que se requiere para que sea posible un Estado constitucional es la existencia de una 
Constitución rígida que consagre un catálogo de valores, principios y derechos fundamentales. Es decir, una Constitución escrita cuyo procedimiento de modificación sea más agravado que el de una ley o de cualquiera otra norma de menor jerarquía. Este hecho supone que la Constitución es la norma de mayor jerarquía del ordenamiento jurídico y es, por tanto, inmune frente a cualquier intento de modificación o sustitución por cualquier otra. Un segundo elemento para hablar de Estado constitucional, en palabras del mismo autor, tiene que ver con la existencia de una garantía jurisdiccional que permita mantener la supremacía constitucional y preservar su máximo nivel de jerarquía cuando quiera que una norma de menor rango transgreda sus principios o reglas. Esta garantía puede ser: i) Abstracta o concreta, según se haga sobre una norma o sobre un caso concreto "efectos erga omnes o inter partes"; ii) A priori o a posteriori, según se haga con anterioridad o posterioridad a la vigencia de una norma de menor jerarquía; iii) Concentrada o difusa, según se haga por un órgano especializado, corte o tribunal constitucional, o se permita a todos los jueces, dentro del ámbito de su competencia.

Continúa Lancheros-Gámez (2009) señalando que la tercera y cuarta característica de un Estado constitucional son respectivamente, el reconocimiento de la fuerza vinculante de la Constitución, en el entendido de que más allá de su contenido o de la forma en que se encuentra redactada, la Constitución, en su carácter de norma superior, condiciona la labor de las autoridades públicas y de los particulares, sin necesidad de norma alguna adicional que así lo prescriba y la interpretación extensiva de la Constitución. Es decir, con la forma como ella es utilizada para llenar las lagunas de sus propias disposiciones, y del ordenamiento jurídico en general, toda vez que es sabido que el ordenamiento jurídico tiene vacíos y que no toda conducta humana o situación jurídica se encuentra regulada.

El quinto rasgo citado por Lancheros-Gámez (2009) está relacionado con la aplicación directa de la Constitución, y como ya fue indicado, está íntimamente ligada al reconocimiento de su fuerza vinculante. Esta aplicación directa se refiere a la extensión de los efectos de la Constitución a las relaciones entre ciudadanos y los poderes públicos, y a las de los ciudadanos entre sí. Ya se veía antes cómo la concepción original de la ley tenía como finalidad esencial limitar el poder de las autoridades públicas frente a los ciudadanos, mientras dejaba a los particulares la libre regulación 
de sus relaciones con algunos límites que fueron interpretados inicialmente de manera restrictiva.

Una sexta característica aportada por el mismo autor es la interpretación conforme a la Constitución, en el entendido de que, si las tres anteriores tienen relación directa con la propia Constitución, esta última tiene que ver directamente con el ordenamiento infra constitucional. Este autor señala que desde una perspectiva conocida, puede afirmarse que la supremacía de la Constitución obliga a adecuar todas las normas de inferior jerarquía a su contenido, hecho que tiene como presupuesto aceptar que se pueden admitir distintas interpretaciones, y que no todas ellas son constitucionales. En este sentido, únicamente las interpretaciones conformes con la Constitución pueden ser admitidas, y solo cuando no sea posible interpretar una norma con los postulados de la norma suprema, ella debería ser declarada inconstitucional por la autoridad competente o inaplicada por los diferentes operadores jurídicos (Lancheros - Gámez, 2009).

\subsection{Los Derechos Fundamentales}

El Estado de derecho incluye la garantía y la seguridad de los derechos fundamentales como una de las calidades básicas del modelo de Estado, toda vez que desde Luigi Ferrajoli, el discurso de los derechos fundamentales aparece como característico de lo que él llama Estado Constitucional de derecho. En donde tanto los derechos fundamentales como los principios constitucionales son paradigmas que definen la validez del ordenamiento jurídico. Por lo que en esta última forma de Estado implica una constitución vinculante en lo formal y en lo sustancial. Sin embargo, en el moderno Estado constitucional de derecho existe una nueva y más poderosa legitimidad del poder judicial diferente a la que existía en el modelo de la Ilustración, y que se basa en el análisis de las siguientes causas: a) Cambio en la concepción de la democracia; b) Cambio de paradigma de Estado de derecho. Al respecto, Luigi Ferrajoli (2003) delimita como principios pertenecientes a los Estados de derecho el vínculo de las ramas de poder a las normas de la Constitución, la división de poderes y los derechos fundamentales. En este mismo sentido, el autor italiano precisa que el respeto o la sujeción a la ley, entendida en sentido estrictamente formal, no indica que se esté en presencia de un Estado de derecho, ya que 
está vinculado con una delimitación a causa de las normas que rebasa las formas y se extiende a los asuntos materiales.

El Estado Constitucional de derecho, tal como lo presenta Ferrajoli, además de las formas de producción legislativas, establece límites al proceso de creación de las normas jurídicas, al configurar prohibiciones y obligaciones que tienen relación con el contenido que no se puede reducir o desmejorar. Obligaciones relacionadas con los derechos de libertad y los derechos sociales, cuya vulneración genera, en sus palabras, "antinomias o lagunas que la ciencia jurídica tiene el deber de constatar para que sean eliminadas o corregidas". De lo anterior expuesto, se puede significar que el desarrollo de los puntos cardinales del derecho constitucional no solo se producen en las directrices constitucionales, pues aquel se desarrolla en todos los aspectos jurídicos y normativos, aunque hay una garantía especial por medio de los mecanismos establecidos para la protección de la Constitución. De modo que cuando se configuran vulneraciones al orden constitucional que no fueron reparadas por la vía ordinaria, a través del ejercicio de las acciones constitucionales, se puede encontrar remedio a las falencias del sistema jurídico que configuran tales vulneraciones. Bajo los anteriores parámetros, entre los contenidos de la Constitución, los derechos son, en este paradigma, la pieza fundamental, toda vez que el modelo atribuye a los derechos el papel de representar la justificación más importante del derecho y del Estado y, por tanto, desde esta perspectiva, el Estado no es sino un instrumento de tutela de los derechos fundamentales y como tal fundamento necesita imponer fines y objetivos que deben ser realizados (Ferrajoli, 2003).

Ferrajoli et al. (2001) señala que son «derechos fundamentales» todos aquellos derechos subjetivos que corresponden universalmente a «todos» los seres humanos en cuanto dotados de status de personas, de ciudadanos o personas con capacidad de obrar; entendiendo por «derecho subjetivo» cualquier expectativa positiva (de prestaciones) o negativa (de no sufrir lesiones) adscrita a un sujeto por una norma jurídica; como presupuesto de idoneidad para ser titular de situaciones jurídicas y/o autor de los actos que son ejercicio de estas, lo cual da contenido a la idea de que en el modelo de Estado constitucional, el derecho y el poder encuentran su legitimidad en un presupuesto de orden externo que no es sino la persona como valor, y la primacía axiológica de este postulado sobre cualquier otro. 
En el caso de la aplicación y la justificación de derechos, las condiciones de prioridad y las estructuras de ponderación cobran una relevancia específica, según hayan sido otorgados por reglas o por principios. Así, según Alexy (1993) existen algunos derechos constitucionales provenientes de reglas que contienen cláusulas que autorizan al parlamento o a la administración a imponer excepciones o limitaciones a su ejercicio. Pero también existen derechos fundamentales otorgados por principios que, en lugar de delimitarse, tenderían a perfeccionarse, dado que los principios son mandatos de optimización que deben realizarse en la mayor medida, atendiendo a las posibilidades fácticas y jurídicas. Para Alexy, los derechos constitucionales deben concebirse como derechos prima facie, es decir, como derechos basados en principios. Ello permite que la aplicación de un derecho fundamental pase de hacerse una tarea de subsunción a un proceso de ponderación. Con esto, Alexy (1993) sostiene que pese a que la teoría del discurso no permite determinar de forma objetiva y definitiva el peso de cada derecho; sin embargo, es capaz de mostrar que son posibles los argumentos racionales acerca de los derechos, lo cual constituye una prueba suficiente de que la inclusión de derechos fundamentales en el sistema jurídico conduce a una conexión conceptual necesaria entre el derecho y la moral.

Con todo lo anteriormente expuesto, la Constitución y los derechos fundamentales no son sino artificios jurídicos que cobran todo su sentido en tanto que límites del poder y garantía de la libertad e inmunidad de las personas, puesto que los derechos existen para maximizar la autonomía de las personas y minimizar el impacto de los poderes (públicos y privados) sobre sus vidas. En suma, los derechos fundamentales son así un contenido básico del orden jurídico, tanto en sentido formal como material, dado que son estos derechos los que disponen límites materiales para los poderes públicos y privados y establecen, asimismo, los fines básicos hacia los que estos deben orientarse. En el Estado constitucional, los derechos fundamentales son a la vez garantías institucionales, normas objetivas del sistema jurídico y derechos subjetivos, en tanto que libertades, potestades, pretensiones e inmunidades normativas protegidas por el ordenamiento jurídico. Junto a esta doble dimensión -objetiva y subjetiva (Pérez Luño, 1998) - se caracterizan por presentar una especial fuerza o resistencia 
jurídica frente a la acción de los poderes públicos, incluido el legislador, y también en las relaciones entre particulares (Prieto Sanchís, 1990).

\section{El Proceso de Constitucionalización en Colombia}

\subsection{La Constitución política de 1991}

En el año de 1991 se adopta en Colombia una Constitución ampliamente influenciada por el constitucionalismo de postguerra (Constitución italiana de 1945, alemana de 1949, española de 1978), donde se reconoce, en algunos aspectos, la tradición constitucional local y se adoptan disposiciones de la Constitución brasilera de 1988. La Carta política de 1991 reconoce igualmente derechos fundamentales y crea mecanismos de protección y efectividad para los mismos, como la acción de tutela que le otorga el control de constitucionalidad de las leyes -que venía siendo ejercido por la Corte Suprema de Justicia desde 1910- a la Corte Constitucional, organismo judicial encargado de velar por la supremacía e integridad de la Carta Política; todo esto bajo la adopción de la fórmula política del Estado Social de derecho.

Adicional a lo anterior, está la promulgación de la Constitución de 1991 que marcó una nueva pauta en el acoplamiento de las disposiciones internacionales ante el orden constitucional interno. Adoptándose a nivel nacional el concepto de Bloque de Constitucionalidad -tal como se utiliza hoy en día- donde se reconoce la jerarquía constitucional de ciertos instrumentos internacionales. Dicha figura ha sido definida por la jurisprudencia constitucional como aquella unidad jurídica compuesta por normas y principios que, sin aparecer formalmente en el articulado del texto constitucional, son utilizados como parámetros del control de constitucionalidad de las leyes, por cuanto han sido normativamente integrados a la Constitución, por diversas vías y por mandato de la propia Constitución. Son pues verdaderos principios y reglas de valor constitucional, por lo tanto, constituyen normas situadas en el nivel constitucional, a pesar de que, a veces, puedan contener mecanismos de reforma diversos contrarios a las normas del articulado constitucional strictu sensu. 
El profesor Rodrigo Uprimny (2001) señala que la Constitución de 1991, respecto del Bloque de Constitucionalidad en el ordenamiento interno, confiere una fuerza jurídica interna clara a los instrumentos internacionales de derechos humanos, toda vez que cuatro disposiciones juegan un papel trascendental: De un lado el artículo 53, según el cual "los convenios internacionales del trabajo debidamente ratificados, hacen parte de la legislación interna". De otro lado, el artículo 93, que establece que ciertas normas internacionales de derechos humanos "prevalecen en el orden interno", y que "los derechos y deberes consagrados en esta Carta, se interpretarán de conformidad con los tratados internacionales sobre derechos humanos ratificados por Colombia". En tercer término, en el artículo 94 se incorpora la cláusula de derechos innominados, pues precisa que "la enunciación de los derechos y garantías contenidos en la Constitución y en los convenios internacionales vigentes, no debe entenderse como negación de otros que, siendo inherentes a la persona humana, no figuren expresamente en ellos". Finalmente, el artículo 214, que regula los estados de excepción indica que, incluso, en esos momentos de crisis, no pueden "suspenderse los derechos humanos ni las libertades fundamentales", y que "en todo caso se respetarán las reglas del derecho internacional humanitario".

Uprimny (2001) señala igualmente que esta amplia apertura de los derechos humanos hacia el derecho internacional, permitió que la Corte Constitucional, desde sus primeras sentencias, y en abierto contraste con la jurisprudencia preconstituyente, utilizara vigorosamente los tratados de derechos humanos para orientar sus decisiones. Así, continúa refiriendo Uprimny (2001), la idea del bloque de constitucionalidad, pues considera que muchas normas que no se encuentran directamente en el articulado constitucional -en especial las disposiciones internacionales de derechos humanos- tienen relevancia constitucional al momento de decidir los casos. En palabras nuevamente de Uprimny (2001) fue importante el cambio jurisprudencial que implicó la expedición de la Carta de 1991 en relación con la fuerza jurídica de los derechos humanos, resultando igualmente notable la manera vigorosa, incluso audaz, cómo la Corte Constitucional interpretó, desde el comienzo de sus labores, los artículos 93, 94 y 214 de la Carta, a fin de potenciar la fuerza jurídica interna de los convenios internacionales de derechos humanos. 


\subsection{La supremacía constitucional}

LasupremacíadelaConstitución Políticasobreelrestode prescripciones del sistema de derecho nacional, es un principio estructurador del orden jurídico, toda vez que interpretando la jurisprudencia constitucional, el conjunto de prescripciones que integran el derecho positivo se ordenan en un sistema normativo, en virtud de la unidad y coherencia que le imprimen los valores, principios y reglas establecidas en la Constitución. En otras palabras, el orden jurídico de la sociedad política se diseña a partir de la Carta Fundamental. De allí que la misma Corte haya dicho que la posición de supremacía de la Constitución sobre las restantes normas que integran el orden jurídico, estriba en que aquélla determina la estructura básica del Estado, instituye los órganos a través de los cuales se ejerce la autoridad pública, y atribuye competencias para dictar normas, ejecutarlas y decidir conforme a ellas las controversias y litigios que se susciten en la sociedad. Por supuesto, al efectuar todo esto, funda el orden jurídico mismo del Estado.

La Corte Constitucional de Colombia (C-415, 2012) en el mismo sentido ha señalado que la noción de supremacía constitucional parte de la naturaleza normativa de la Constitución, que se revela en el carácter de fuente primaria del ordenamiento jurídico. De allí que el artículo 4 de la Constitución Política indica: "La Constitución es norma de normas. En todo caso de incompatibilidad entre la Constitución y la ley u otra norma jurídica, se aplicarán las disposiciones constitucionales". Así, la naturaleza normativa del orden constitucional es la clave de la sujeción del orden jurídico restante a sus disposiciones, en virtud del carácter vinculante que tienen sus reglas. Tal condición normativa y prevalente de las normas constitucionales, la sitúan en el orden jurídico como fuente primera del sistema de derecho interno, comenzando por la validez misma de las normas infra constitucionales cuyas formas y procedimientos de producción estén reguladas en la propia Constitución. De ahí que la Corte (C-415, 2012) haya expresado:

La Constitución se erige en el marco supremo y último para determinar tanto la pertenencia al orden jurídico como la validez de cualquier norma, regla o decisión que formulen o profieran los órganos por ella instaurados. El conjunto de los actos de los órganos constituidos -Congreso, Ejecutivo 
y jueces- se identifica con referencia a la Constitución y no se reconoce como derecho si desconoce sus criterios de validez. La Constitución como lex superior precisa y regula las formas y métodos de producción de las normas que integran el ordenamiento y es por ello "fuente de fuentes", norma normarum. Estas características de supremacía y de máxima regla de reconocimiento del orden jurídico propias de la Constitución, se expresan inequívocamente en el texto del artículo 4.

(...)

Las consecuencias que se derivan del principio de supremacía -ha agregado esta corporación- apuntan no sólo al reconocimiento de una norma jurídica como piedra angular filosófico-política que rige todas las actividades estatales, y a la cual están subordinados todos los ciudadanos y los poderes públicos, sino que legitima además las normas jurídicas que se expidan congruentes con ella.

También el concepto de supremacía normativa de la Carta Política es definitorio del Estado Social y constitucional de derecho. En virtud de la fuerza normativa de la Constitución, las autoridades no solo se hallan sometidas al derecho positivo presidido por la norma superior, en el ejercicio de sus competencias; también para la realización efectiva de los derechos subjetivos consagrados constitucionalmente. Ante dichas autoridades los ciudadanos pueden exigir la realización efectiva de los derechos constitucionales, algunos de los cuales son de "aplicación inmediata" -al tenor del artículo 85 constitucional-, merced, precisamente, a su fuerza normativa vinculante. De este modo, la supremacía normativa de las normas constitucionales se erige en un principio clave para la concreción del catálogo de derechos fundamentales y la efectividad de los demás derechos consagrados en la Carta Fundamental (Corte Constitucional de Colombia, C-415, 2012).

En tal sentido, la Corte ha considerado que: la Constitución es norma fundante en una dimensión tanto axiológica (v. gr. establece principios, derechos fundamentales y pautas interpretativas), como instrumental (proporciona los mecanismos para lograr armonía y coherencia en la 
aplicación de la Constitución). En ese orden de ideas, el principio de supremacía da cabida a la consagración de garantías fundamentales como fines prioritarios del Estado, y el establecimiento de controles de todo el ordenamiento y de una jurisdicción especial encargada de velar por su integridad. Tal jurisdicción especial no es otra que la jurisdicción constitucional, en cuyas decisiones deposita la propia Constitución la guarda de su integridad y supremacía (Corte Constitucional de Colombia, C-415, 2012).

La supremacía constitucional es elaborada a nivel teórico por Kelsen (1974), quien en su obra La Teoría Pura del derecho, explica que el ordenamiento jurídico se organiza normativamente en una jerarquía, por lo cual debe tener un punto de partida que lo fundamente, encontrando esta base en la Constitución. Así entonces podemos afirmar que la Constitución es ley fundamental, en primer lugar, porque define el sistema de fuentes formales del derecho; y en segundo término, tal como asegura García de Enterría (1985), por tener una pretensión de permanencia, de base estable de la organización de un Estado. La Constitución como norma suprema no es tan sólo un criterio que la hace superior a las demás normas, sino que también es punto de unidad del ordenamiento, implica la existencia de coherencia y sistematización entre las reglas de derecho que rigen en un Estado determinado.

Para completar el planteamiento anterior, es necesario señalar que la supremacía de la Constitución da prevalencia a los derechos fundamentales. La existencia de inalienabilidad de los derechos les otorga un plus de permanencia, y la presencia de un mecanismo expedito que los haga valer les da una trascendental garantía. Es decir, en palabras del mismo tratadista Kelsen, la Constitución es concebida como norma de normas y se resalta así el hecho de su superioridad sobre las demás disposiciones del ordenamiento jurídico, pues se la dota además de un carácter normativo, mediante el cual puede ser aplicada en alguna de sus apartes, de forma directa por los jueces sin necesidad de desarrollo legal. La primacía de los derechos inalienables de las personas otorga un estatus trascendente a la concepción de persona y sus derechos fundamentales.

\subsection{El control constitucional}


Como lo ha dicho la Corte Constitucional (C-415, 2012), la supremacía normativa de la Constitución tiene como su principal garantía la existencia del control de constitucionalidad, a cargo de determinados órganos del poder judicial. Señala la Corte que, en principio, todos los poderes públicos deben velar porque la producción del derecho se ajuste a las reglas formales y contenidos materiales del orden constitucional. Del mismo modo que sus actuaciones concretas, por lo que así, los actos del gobierno, la actuación de las autoridades administrativas -y de algunos particulares en casos especiales-, las mismas decisiones de los jueces y los actos de legislación, se hallan dominados por el principio de supremacía de la Constitución, y sujetos a diversos tipos de exámenes de constitucionalidad de los mismos. En unos casos a través de mecanismos de control concreto de la constitucionalidad de las actuaciones públicas - por vía de acción o excepción- y en otros eventos mediante modalidades de control abstracto de los actos legislativos, las leyes y otras normas generales, por vía de acción o por ministerio de la Constitución.

El Constituyente de 1991 - ha señalado igualmente la Corte (C-415, 2012) - optó por un modelo de control constitucional que la jurisprudencia ha llamado difuso funcional. En este esquema concurre, por un lado, la Corte Constitucional y el Consejo de Estado, como órganos encargados del control abstracto de constitucionalidad y, por el otro, todos los jueces y corporaciones que deben decidir las acciones de tutela o resolver acciones y recursos previstos para garantizar los derechos constitucionales o al hacer uso de la excepción de inconstitucionalidad en los casos concretos sometidos a su consideración. Lo anterior significa que en Colombia no existe una jurisdicción y un control constitucional concentrados, lo cual quiere decir que la jurisdicción constitucional la despliegan distintos órganos de la rama judicial. A la Corte Constitucional corresponde, como lo establece el artículo 241 de la Constitución, la guarda de la integridad y supremacía de la Constitución, y al Consejo de Estado corresponde, según el artículo 237 de la Constitución, conocer de las acciones de nulidad por inconstitucionalidad de los decretos dictados por el Gobierno Nacional.

Pese a que sistema de guarda de la Carta de 1991 establecido en Colombia es abierto e integral, actualmente el control constitucional interno se mira más a partir del estudio de los efectos de las sentencias de la Corte Constitucional, que según el artículo 48 de la Ley 270 de 1996 (Estatutaria 
de la Administración de Justicia) son las mismas dictadas como resultado del examen de las normas legales, ya sea por vía de acción, de revisión previa o con motivo del ejercicio del control automático de constitucionalidad. Sólo serán de obligatorio cumplimiento y con efecto erga omnes en su parte resolutiva, constituyéndose la parte motiva como criterio auxiliar para la actividad judicial, y para la aplicación de las normas de derecho en general. Igualmente señala la normativa citada que la interpretación por vía de autoridad que hace la Corte Constitucional, sin duda, tiene carácter obligatorio general.

Reseña López (2011) que el desarrollo de la jurisprudencia de la Corte Constitucional colombiana ha generado un alto grado de aceptación entre la sociedad, debido a la protección ordenada en las sentencias de la Corte en materia de defensa de los derechos fundamentales, derechos sociales y excepcionalmente derechos colectivos. Adicional al hecho de que se le encomendó la importante misión de unificar la jurisprudencia mediante la revisión de las acciones de tutela, y de velar por la supremacía de la Constitución, por medio de los fallos de constitucionalidad. Indica López (2011) que esta vasta tarea impuesta a la Corte ha permitido desarrollar una extensa doctrina constitucional jurisprudencial que, a su vez, ha permitido construir unas bases sólidas sobre las cuales se ha venido edificando el constitucionalismo colombiano del siglo XXI. Convirtiéndose el Tribunal, incluso, en el último eslabón de la pirámide del poder público en Colombia. Cualquier controversia, por banal que sea, es susceptible de constitucionalizarse, y con ello la discusión no se puede considerar cerrada hasta tanto la Corte no se pronuncie sobre el asunto.

A pesar de su importante labor en defensa de la Carta superior, relata nuevamente López (2011) que el control desplegado por la Corte Constitucional colombiana ha generado numerosas críticas. Entre otras cosas, por las modificaciones efectuadas a las leyes por medio de las cuales, ordena la imposición de un efecto no previsto por el legislador, generándose de esta forma un clima de inseguridad jurídica al invadir los campos del legislativo. Pero en palabras del mismo autor, una de las mayores críticas que podría hacérsele a la Corte, gravitaría en que esta ejerce un "gobierno de los jueces", demostrándose en el hecho de que el Tribunal está compuesto de algunas personas arbitrariamente designadas, y sin responsabilidad política, a menudo nombradas por complacencia o 
por coyunturas políticas, que forman un cuerpo poco democrático, con un poder ampliamente decisivo y sin control. Troper, constitucionalista francés y profesor de la Universidad de París, afirmó en el año 2011 que el hecho de que los jueces tomen decisiones políticas parecería una contradicción ya que los jueces no gobiernan. Los jueces juzgan y se pronuncian por razones de legalidad y no de oportunidad (López, 2011).

Sobre el conflicto entre la democracia y la justicia constitucional, en el entendido que el control constitucional de las leyes que ejercen los jueces constitucionales (función de legislador negativo) contraría la decisión de las mayorías legislativas que aprueban alguna ley, la cual, luego de someterse al examen constitucional, resulta no ser válida, ha tenido múltiples representantes. Ferreres (1997) afirmó que no puede justificarse que en una democracia la decisión de la mayoría parlamentaria acerca de los derechos y las libertades pueda ser invalidada por un juez. Ante esta situación existe una excepción como es la de esta regla general: si la decisión de la mayoría parlamentaria atenta contra los derechos que dan acceso al proceso político, entonces está justificado que el juez pueda invalidar la ley. Ello es así porque el Parlamento goza de legitimidad en la medida en que es un órgano democrático, pero si el parlamento erosiona los derechos de participación política a través de los cuales los ciudadanos dan vida al proceso democrático, socava entonces su propia legitimidad democrática, con la consecuencia de que se justifica en esos casos que el juez pueda controlar la ley. Puntualiza Ferreres (1997) que este rol de guardián de la regularidad del proceso político es el único papel que en una democracia debería desempeñar el juez constitucional. Indudablemente, y pese a las críticas que pueda recibir, no existe duda alguna del carácter normativo y fundamental de la Constitución. Sin embargo, se la debe proteger y defender frente a los poderes públicos, cuando estos tiendan a desconocerla. Como lo señala García de Enterría (1985), toda vez que la propia constitución gradúa la fuerza normativa de sus disposiciones, y se 
encarga de predisponer un completo sistema de garantías, que asegure el respeto a su supremacía.

\section{Incidencia en el sistema jurídico nacional}

\subsection{Supremacía de los derechos fundamentales}

La Constitución de 1991 o Carta Política de navegación, como suelen llamarla algunos, proclamó en Colombia un Estado Social y democrático de derecho con una democracia participativa. Además, consagró una extensa gama de mecanismos para hacer efectiva dicha participación, así como un catálogo bastante amplio de los derechos del ciudadano. Entre estos que resaltan los derechos fundamentales, los colectivos y del medio ambiente, estableciendo a su vez los mecanismos de protección para la defensa de todos los derechos, que pasaron de ser meros enunciados retóricos a verdaderos derechos exigibles ante las autoridades administrativas y, en última instancia, ante las judiciales.

En este modelo de Estado constitucional, los derechos fundamentales pueden ser pensados como límites o prohibiciones que afectan al legislador, ya que los derechos no son ilimitados, no son absolutos, pero tienen un contenido constitucionalmente tipificado o predeterminado $\mathrm{y}$, salvo habilitación expresa, no deben ser cercenados por el legislador. Bajo esta nueva perspectiva, el legislador no puede introducir límites a los derechos donde la Constitución no lo hace. Sin embargo, no se alcanza a sostener la idea de que entre los derechos constitucionales y entre sus límites, haya fronteras nítidas, o que es posible formular un catálogo taxativo de los supuestos de hecho y sus excepciones correspondientes a los enunciados de derechos constitucionales. La concepción fuerte de la nueva Constitución y, en especial, de los derechos fundamentales, mediante la cual estos revelan la potestad de irradiar el ordenamiento jurídico y condicionar situaciones que otrora regulaba la ley o estaban sometidas al arbitrio de los privados, comenzó a desarrollar la constitucionalización de todo el ordenamiento jurídico interno. De esta manera, los textos constitucionales, y, muy en 
particular, aquellos en los que se consagran derechos fundamentales de las personas, se han convertido en principios y reglas directamente aplicables a todo tipo de conflictos jurídicos, que deben resolver los legisladores, jueces y funcionarios administrativos en Colombia.

\subsection{Interpretación desde la Constitución}

Francisco Rubio Llorente prologando a Alonso García (1984) resalta el cambio operado en la Teoría de la Interpretación que ha pasado de ser patrimonio de los civilistas a instrumento de uso corriente de publicistas, constitucionalistas y administrativistas. Presentándose una nueva estructura relacional entre la Constitución y la Ley que se pone de relieve con la expresión la Constitución como norma jurídica. Al respecto, Insignares Gómez (2011) refiere que uno de los temas que cobra mayor vigencia en el modelo de Estado que actualmente acompaña a las democracias liberales en el mundo, es aquel que hace referencia al papel orientador que cumple la Constitución como pilar de los valores y punto de referencia necesario para el diseño de los sistemas jurídicos. De otra parte, autores como Stern, citado por Alonso García (1984) señalan que el problema genérico o global de la interpretación constitucional se ha convertido en el problema cardinal de la interpretación como fenómeno jurídico.

Ahondando en el tema, Insignares Gómez (2011) señala que cuando se habla de investigar el significado de las normas constitucionales nos topamos con el inconveniente de que la mayoría de enunciados constitucionales con relevancia sustantiva hacen referencia, como bien lo indica Larenz, a pautas que precisan ser llenadas de contenido, a cuya concreción están llamados tanto el simple legislador como la jurisprudencia de los tribunales (Alonso García, 1984). Ya sea en principios o en valores, esta naturaleza de dichos enunciados, continúa Insignares Gómez (2011), implica que la tarea adelantada por el intérprete se cobije de una especial importancia, toda vez que su resultado debe ajustarse a la filosofía que implicó el nacimiento de los principios y de su criterio axiológico. Además, señala el mismo autor, que esto es menester tenerlo en cuenta ya que en la interpretación constitucional se carece de un marco normativo que sirva de referencia. Por lo que corresponde al legislador, en primera instancia, especificar la norma constitucional, dotándola de contenido y de fuerza de aplicabilidad. Por su parte, los tribunales, cuando el legislador ha dado concreción a la norma, 
se encuentran vinculados a ella y no pueden apartarse so pretexto de una interpretación conforme a la Constitución, que implique una corrección de la ley.

No obstante, esto lo refuta Insignares Gómez (2011), pues en los eventos en que la regulación del legislador se opone abiertamente al principio o al valor constitucional originando con ello que no haya una especificación del principio sino una tergiversación -entonces están en posibilidad los tribunales de negar la validez de la ley por ser anticonstitucional- y en consecuencia, sólo podrá un tribunal concretar de manera inmediata una norma constitucional cuando existe una omisión de la ley o cuando la otorgada por esta reviste un carácter insuficiente, originando con esto una laguna legal. Al respecto puede hacerse eco de los argumentos de Alonso García (1984) quien, al referirse a esta labor de los tribunales en la interpretación constitucional, manifiesta: "Nuestra misión es a la vez más amplia y más limitada. Parte de una idea que enlaza ambos conceptos de interpretación: la de que para los juristas la interpretación constitucional es un fenómeno peculiar, pues si, por un lado, tienen que dialogar con el intérprete auténtico en términos estrictamente jurídicos, utilizando los métodos clásicos de interpretación; por otro, tiene que hacerse eco del fenómeno de la interpretación constitucional como vivencia constitucional 'para justificar las vivencias del texto fundamental', convirtiéndose así en lenguaje jurídico, asimilable por el intérprete auténtico, formas culturales de vivencia de valores e ideas como fundamentales".

Además de lo ya dicho, Insignares Gómez (2011) asegura que cuando se habla de interpretación constitucional, no sólo nos referimos al problema de subsumir un determinado supuesto de hecho en una norma de la Carta Política, lo cual implica unas dificultades por la indeterminación de muchos de los conceptos consagrados en la Constitución, sino que también es relevante tener en cuenta que en los países donde hay una jurisdicción constitucional "el intérprete judicial crea y formula normas derivadas de la Constitución, bien expresa, bien implícitamente" (Alonso García, 1984). Recalca Insignares Gómez (2011) que esta operación adelantada por los jueces es la que denomina el profesor Enrique Alonso García como la producción de una doctrina, o, siendo más precisos, la creación de normas subconstitucionales que orientan la aplicación de la norma en cuestión. En tal sentido, señala dicho autor, la interpretación constitucional se constituye 
en un mecanismo racional y científico-jurídico, por el que la vivencia popular de lo fundamental llega a convertirse en norma subconstitucional equivalente a la Constitución misma.

Ahora bien, cuando los tribunales constitucionales proceden a dar una interpretación de la Constitución, en palabras de Insignares Gómez (2011), el problema se centra en establecer si el método utilizado para esto se reviste de un carácter político o jurídico. Al respecto Alonso García (1984) afirma que el objeto sobre el que recae el enjuiciamiento es la gran política, y no las pequeñas políticas sectoriales que se realizan en las normas inferiores. Lo que, a su vez, conlleva que sea inevitable tener en cuenta las consecuencias políticas de los pronunciamientos, ya que en la célebre expresión de Bachog 'estas sentencias (constitucionales) pueden ocasionar catástrofes no sólo para el caso concreto, sino para un indivisible número de casos, cuando estas sentencias son políticamente inexactas y falsas' (en el sentido de que desbaratan las tareas políticas legítimas de la dirección del Estado), la lesión puede alcanzar a la comunidad política entera.

En consonancia con lo anterior, el tratadista Insignares Gómez (2011) concluye que el tamiz político de las decisiones de los tribunales constitucionales convive con el jurídico, por lo cual debe cuidarse mucho la jurisdicción de no caer en el error de "oracular", en el proceso de creación de las normas subconstitucionales, ya que con ello se pone en riesgo no sólo la estabilidad jurídica sino también la política. Es así como, finaliza el mismo autor citado, en no pocas oportunidades el grado de indeterminación es de tal talante, que el juez puede considerar que su hechura obedece al legislador como legítimo representante del pueblo.

\subsection{Valor jurídico de las normas constitucionales}

Con base en lo dicho hasta el momento, resulta importante recordar la pregunta de Sainz Moreno (1982): ¿Cómo se articula técnicamente el valor normativo directo y general de la Constitución? Por su parte, García de Enterría (1985) lo expone resumidamente admitiendo que el monopolio jurisdiccional del Tribunal Constitucional sólo alcanza a la declaración de inconstitucionalidad de las leyes (monopolio de rechazo), no a cualquier aplicación de la Constitución, sin perjuicio de que el Tribunal pueda también conocer de los reglamentos de las Comunidades autónomas. Esto implica que la prohibición de declaración de inconstitucionalidad por 
otros Tribunales y Juzgados no alcanza ni a normas de rango inferior a la ley ni a actos jurídicos públicos o privados, e implica también que no se prohíbe sino que se obliga a los órganos judiciales a realizar "juicios de constitucionalidad positiva" (de conformidad de la ley con la Constitución) y a interpretar constitucionalmente la totalidad del ordenamiento.

De lo expuesto anteriormente, y de acuerdo con los principios de sometimiento al imperio de la ley y de iura novit curia, García de Enterría (1985) observa que a todos los Tribunales corresponde, al menos: a) El enjuiciamiento previo de constitucionalidad a los efectos de hacer un juicio de posible inconstitucionalidad de la norma con el consiguiente planteamiento de la llamada «cuestión de inconstitucionalidad», o un juicio positivo de constitucionalidad que condiciona toda aplicación de una ley. b) El juicio de posible inconstitucionalidad de los reglamentos. c) El juicio de inconstitucionalidad de actos jurídicos públicos y privados. d) La interpretación de la totalidad del ordenamiento conforme a la Constitución. García de Enterría igualmente refiere que la vinculación a la Constitución por parte de los tribunales y de todos los sujetos públicos y privados, se extiende a todas las normas constitucionales. De modo que aquí no cabe la distinción entre artículos de aplicación directa y artículos programáticos, sin valor normativo. En definitiva, puntualiza el mismo autor que todos los preceptos constitucionales, cualquiera que sea el grado de su concentración, son aplicables, ya que no existen en la Constitución declaraciones a las que no haya que darle valor normativo.

Tomando las anteriores pautas e interpretando a Sainz Moreno (1982), se puede afirmar que la Constitución Política de Colombia de 1991, ocupa un privilegiado lugar en el ordenamiento jurídico nacional, que obliga a aplicar e interpretar dicho sistema siempre de conformidad con los principios y reglas constitucionales, toda vez que el origen del principio de interpretación conforme a la Constitución está en el proceso de constitucionalidad de las leyes. Al respecto señala Sainz Moreno (1982) que este principio conecta con la "presunción de constitucionalidad de las leyes", de modo que una ley sólo será declarada inconstitucional cuando no exista duda razonable sobre ella. En el mismo sentido, García de Enterría (1985) refiere que la interpretación de una norma conforme a la Constitución, no sólo obliga a determinar cuáles son los principios constitucionales, sino también el orden de valores que hacen que la Constitución tenga 
una unidad material de sentido que conlleve a la necesidad de realizar una interpretación de los principios constitucionales mismos. Tal modo de actuar impone algunas consecuencias, que García de Enterría (1985) esquematiza de acuerdo a los siguientes postulados:

1. La Constitución es el contexto de todas y cada una de las leyes, reglamentos y normas del ordenamiento a efectos de su interpretación y aplicación.

2. La Constitución prevalece no sólo en la interpretación declarativa, sino también en la interpretación integrativa.

3. Resulta prohibida cualquier construcción interpretativa y dogmática que concluya en un resultado directa o indirectamente contradictorio a los valores constitucionales.

Las normas constitucionales son, pues, en criterio de García de Enterría (1985) normas dominantes frente a todas, en la concreción del sentido general del sistema jurídico. La doctrina legal que resulta de las sentencias del Tribunal o Corte Constitucional tiene un valor preeminente frente a cualquier otro cuerpo jurisprudencial. Preeminencia tanto en el caso de que la sentencia declare la inconstitucionalidad de una norma como en el de que sólo realice una interpretación en consonancia con la Constitución, aunque en este último caso no prevalezca como ley, sino como tal doctrina, y sólo en cuanto que la intervención del Tribunal Supremo suponga una colisión con la Constitución. De todo lo anterior resulta la función preeminente que desempeña la Corte Constitucional, sin desconocer, claro está, que dicha Corte también decide conflictos políticos. Pero lo característico, en palabras nuevamente de García de Enterría (1985), es que la resolución de los mismos se hace por criterios y métodos jurídicos, y esto no sólo formalmente (según la famosa objeción de Schmitt, de que la justicia constitucional sólo es judicial en la forma), sino materialmente por medio de la razón llamada derecho. Lo que lleva, en definitiva en la actualidad, a situar los criterios de fondo que fundamentan sus decisiones como tema central de la jurisdicción constitucional. Los mismos que, sin lugar a dudas, inciden ampliamente en nuestro sistema jurídico.

\section{Referencias}

Alexy, R. (1993). Derecho Y Razón Práctica. México: Fontamara. 
Alexy, R. (1993ª). Teoría De Los Derechos Fundamentales. Madrid: Centro De Estudios Constitucionales.

Alonso García, E. (1984). La Interpretación De La Constitución. Madrid: C.E.C.

Arrieta Flórez, V. (2009). La Constitucionalización Del Derecho Y Su Incidencia En Colombia, En Revista Pensamiento Americano, 2, 2.

Corte Constitucional De Colombia, (2012). Sentencia C-415 Del 06 De Junio De 2012. M.P. Mauricio González Cuervo. Bogotá D.C., Colombia: Rama Judicial Del Poder Público.

Ferrajoli, L., Pisarello Prados, G, Bacelli, L \& De Cabo, A. (2001). Los Fundamentos De Los Derechos Fundamentales. Madrid: Trotta.

Ferrajoli, L. (2003). Pasado Y Futuro Del Estado De Derecho, En Neoconstitucionalismo(S), Miguel Carbonell (Ed.), Madrid: Editorial Trotta.

Ferreres Comella, V. (1997). Justicia Constitucional Y Democracia. Madrid: Centro De Estudios Políticos Y Constitucionales.

García De Enterría, E. (1985). La Constitución Como Norma Y El Tribunal Constitucional. Madrid: Editorial Civitas.

Insignares Gómez, R. (2011). La Interpretación De La Ley, En Revista De Derecho Fiscal. Bogotá: Universidad Externado De Colombia, 1.

Kelsen, H. (1974). La Teoría Pura Del Derecho. México: Editora Nacional. Lancheros-Gámez, J. (2009). Del Estado Liberal Al Estado Constitucional. Implicaciones En La Compresión De La Dignidad Humana. Díkaion, 18.

López Daza, G. (2011). El Juez Constitucional Colombiano Como Legislador Positivo: ¿Un Gobierno De Los Jueces?, En: Revista Mexicana De Derecho Constitucional, 24.

Perez Luño, A. (1998). Los Derechos Fundamentales. Madrid: Tecnos.

Prieto Sanchís, L. (1990). Estudios Sobre Derechos Fundamentales. Madrid: Debate.

Sainz Moreno, F. (1982). La Constitución Como Norma Jurídica Y El Tribunal Constitucional, De Eduardo García Enterría, En Revista Española De Derecho Constitucional. Madrid: Centro De Estudios Políticos Y Constitucionales, 2, 6. 
Sartori, G. (2005). Ingeniería Constitucional Comparada. México: Fondo De Cultura Económica.

Uprimny, R. (2001). El Bloque De Constitucionalidad En Colombia. En: Compilación De Jurisprudencia Y Doctrina Nacional E Internacional. Bogotá: Oficina Del Alto Comisionado De Naciones Unidas Para Los Derechos Humanos. 